\begin{tabular}{|l|l|l|l|}
\hline & ESCOLA DE \\
\hline PUCRS & HUMANIDADES & Caderno Marista de Educação, Porto Alegre, v. 12, n. 1, p. 1-6, jan.-dez. 2021 \\
\hline http://dx.doi.org/10.15448/2763-5929.2021.1.40798 & \\
\hline
\end{tabular}

SEÇÃO: ARTIGOS

\title{
A habilidade de se reinventar em tempos de pandemia
}

The ability to reinvent yourself in times of pandemic

Michelle Okrazewski da Cunha $^{1}$

orcid.org/0000-0002-5264-3898 michelle.cunha@maristas.org.br

\section{Caroline dos Santos Klein ${ }^{1}$}

orcid.org/0000-0003-2309-5543 caroline.klein@maristas.org.br

\section{Tanusa Dresch ${ }^{1}$}

orcid.org/0000-0002-1589-0435 tanusa.dresch@maristas.org.br

Recebido em: 23 abr. 2021 Aprovado em: 17 jun. 2021 Publicado em: 13 set. 2021
Resumo: O presente artigo busca relatar a experiência realizada por três professoras do primeiro ano do ensino fundamental do Colégio Marista Assunção, as quais durante o período de pandemia, associada à COVID-19 no ano de 2020, tiveram de reinventar suas práticas pedagógicas. Tem como ponto de partida o ensino a distância, pois frente às decisões governamentais, decidiu-se pela paralisação das aulas presenciais e transformação destas para a modalidade de ensino remoto, a qual tem por objetivo, aulas ministradas remotamente sem a necessidade da presença física. Contudo, tal modalidade, até então, não era tão abrangente para os anos iniciais. Partiu-se, assim, de uma proposta diferenciada, alicerçada nas metodologias ativas, entre elas a sala de aula invertida, que possibilita reorganizar o espaço-tempo e mobilizar o protagonismo dos estudantes. Palavras-chave: Pandemia. Reinventar as práticas pedagógicas. Alfabetização. Ensino remoto.

Abstract: This article seeks to report the experience of three teachers of the first year of elementary school at Colégio Marista Assunção, who during the pandemic period, associated with COVID-19 in 2020, had to reinvent their pedagogical practices. Its starting point is distance learning, as in the face of government decisions, it was decided to suspend classroom classes and transform them to the remote learning modality, which aims to teach classes remotely without the need for physical presence. However, this modality, until then, was not so comprehensive for the early years. Thus, starting from a differentiated proposal, based on active methodologies, including the inverted classroom, which makes it possible to reorganize space-time and mobilize the protagonism of students. Keywords: Pandemic. Reinvent pedagogical practices. Literacy. Remote teaching.

\section{"Precisamos aprender a conectar coração e tecnologia e seguir buscando reali-} zações que deem significado a nossas vidas e às de outras pessoas".

(Catanante, 2000, p. 40)

\section{Introdução}

Em meados do mês de março de 2020, após um retorno de férias, a escola respirava novamente, em um movimento constante de entrar e sair de crianças, barulhos pelos corredores e a esperança de um ano letivo sem igual.

No entanto, uma notícia muito distante, vinda de um país do qual não tínhamos muita familiaridade, a China, fez com que esse pulsar dos corações parasse e refletisse sobre uma situação inusitada. 
Um virus se proliferou pela cidade, ninguém sabia de sua procedência, nem mesmo do seu real poder, assim, passou a angustiar também a nós nesse momento delicado, por isso, em meio a muitas notícias e estudos, no dia 17 de março, decidiu-se parar as aulas presenciais inicialmente por 15 dias, com retorno previsto, então, para o dia 31 do mesmo mês.

Contudo, nos corredores a notícia tomou outras proporções, pois a incerteza causada por algo tão incomum, fez com que nós educadores saíssemos com a certeza de que era necessário o período de resguardo, porém com a insegurança de quais reais proporções a situação iria tomar.

\section{As concepções Maristas}

Nosso fundador, São Marcelino Champagnat, construiu seu legado alicerçado em uma "pedagogia muito prática, focada na presença, no amor à natureza, na solidariedade e no aprender fazendo" (UNIÃO MARISTA DO BRASIL, p. 12, grifo nosso).

Quando diz muito prática, refere-se às vivências do tocar, do experimentar, do fazer e do sentir. Focada na presença significa estar presente e se fazer presente, ouvindo e trocando aprendizagens. No amor à natureza, contemplando suas singularidades e desfrutando de seus prazeres.

Mas esta pedagogia tão singular neste cenário atual, em que todas as aprendizagens se constituem distantes ao nosso olhar, sem toque, sem afeto e sem trocas presenciais, tão essenciais, fizeram com que os educadores buscassem uma nova forma de permanecer nesse caminho. Buscando, a partir dos ensinamentos de São Marcelino, através da solidariedade e do aprender fazendo, reinventar o cenário da educação nestes tempos de isolamento social.

\section{Método}

O presente artigo é um estudo descritivo, do tipo relato de experiência, realizado a partir da vivência docente, no ensino a distância, que se fez necessário durante o período de pandemia, devido à COVID-19, compreendidos entre março e junho do ano de 2020.
Neste artigo, apresenta-se a análise da vivência realizada pelas docentes Caroline Klein Ribeiro, Michelle Okrazewski da Cunha e Tanusa Dresch, que atuaram no Colégio Marista Assunção, situado em Porto Alegre e tiveram, ao longo dessa trajetória, a oportunidade de evidenciar as suas práticas na modalidade de ensino remoto, com as turmas de primeiro ano do ensino fundamental, em que são professoras titulares.

Destaca-se que as docentes, em suas histórias de vida, não possuíam vivências na modalidade em questão, a não ser como estudantes, quando da realização de formações para aperfeiçoamento profissional. Assim, a experiência foi de suma importância para sua formação pedagógica, bem como para sua reflexão sobre a prática docente em classes de alfabetização a distância.

\section{Relato de experiência}

Diante da situação inicial, foi proposto pela Rede Marista que os educadores usufruissem da ferramenta on-line, denominada Marista 3.0, para postagens de atividades domiciliares, a fim de manter uma rotina para os estudantes, assim como uma aproximação com a escola.

Contudo, devido à falta de prática das professoras na modalidade e dentro do atual cenário que se constituiu, sem grandes explicações sobre a forma mais coerente de trabalho, foram pensadas atividades, posteriormente descritas em um documento e disponibilizadas na ferramenta acima citada.

Uma importante reflexão é que o planejamento das professoras se baseia em documentos pensados para uma prática presencial na Rede, sendo eles o Projeto Educativo e as Matrizes Curriculares do Brasil Marista. Destacando desses uma pedagogia sociointeracionista que, segundo Vigotsky, é uma teoria baseada, em:

\footnotetext{
Um desenvolvimento infantil, como um processo dinâmico, pois as crianças não são passivas, meras receptoras de informação que estão à sua volta, mas sim através do contato com o seu próprio corpo, com as coisas do seu ambiente, bem como a interação com outras crianças e adultos, assim as crianças vão desenvolvendo, a capacidade afetiva, a sensibilidade e autoestima, o raciocínio, o pensamento e a linguagem (VIGOTSKY, 1993, p. 27).
} 
A partir desse pressuposto, refletiu-se que a forma de planejamento deveria propor atividades domiciliares em que não fosse necessário a intervenção do professor, pois este é um ato político e específico e que não podemos atribuir tal tarefa às familias, as quais já viviam em um momento muito sobrecarregado de afazeres, assim como não levasse em consideração a interação entre os pares.

O conhecimento sobre as turmas de primeiro ano em questão e sobre as familias era muito superficial, devido ao pouco tempo que as docentes tiveram para construir relações com os sujeitos. Com isso, fez-se necessário planejar a partir das concepções de familia das educadoras, mas que poderiam estar equivocadas.

As informações para análise eram de três turmas de primeiro ano, composta por: turma 111, com vinte e um estudantes; turma 112, com vinte e três estudantes; e turma 113, com vinte e um estudantes, totalizando 65 sujeitos. Desses, em uma testagem prévia nas aulas presenciais, observou-se estarem em diferentes niveis de alfabetização, sendo, em sua grande maioria, silábicos - etapa em que a criança percebe que a escrita representa aquilo que é falado e associa uma letra para cada sílaba oral -; um grupo silábico alfabético, que já associa valor sonoro à escrita; e um percentual pequeno, alfabéticos, que já conseguem ler e expressar graficamente o que pensa ou fala.

Assim, pode-se perceber que, apesar de se tratar de crianças com realidades distintas, mas em sua maioria de uma classe social privilegiada, elas têm uma experiência prévia de letramento, dentro da normalidade, vindo ao encontro do que diz Emilia Ferreiro (2016):

A aquisição da representação escrita da linguagem tem sido tradicionalmente considerada como uma aquisição escolar (isto é, como uma aprendizagem que ocorre, do início ao fim, no contexto escolar). Ora, sabemos que, entre os conhecimentos fundamentais, praticamente não há dominios dos quais possamos identificar um inicio propriamente escolar. Em todos esses domínios, aos quais a pesquisa psicogenética trouxe dados sólidos, o começo do conhecimento pôde ser situado em torno de um limite pré-escolar (é especialmente o caso das noções numéricas elementares, da organização do espaço, das seriações temporais, da estruturação das relações e dos objetos físicos) (FERREIRO, [2016]).
Portanto, os conteúdos domiciliares deveriam levar em consideração essas diferentes aprendizagens, assim como estender práticas de organização de um ambiente alfabetizador, entendendo assim ser possivel as docentes servirem de tutores para as familias, a fim de promover o seu pensamento para bem educar os estudantes no âmbito pedagógico, mesmo diante da sua falta de formação. Trazendo o preceito de pais-tutores do processo de uma educação em formato homeschooling.

Desta forma, foi reformulada a disponibilização dos conteúdos, tendo a ideia de promover vídeos autoexplicativos para auxiliar, não só os estudantes, mas também elucidar conceitos para as familias. A partir da familiarização com o grupo e da identificação das necessidades, as docentes iniciaram um trabalho conjunto, contemplando, assim, uma pedagogia diferenciada, de modo que, devido às diversidades encontradas no grupo, formulavam e formatavam vídeos com intuito de trabalhar as áreas do conhecimento e as respectivas habilidades a serem desenvolvidas, com vista de atingir as mais distintas realidades.

Sendo assim, a docência compartilhada não deve assemelhar-se a dividir o trabalho, mas sim, multiplicar as possibilidades, pois nada melhor do que a visão combinada de mais pessoas envolvidas em um processo com um fim comum para promover a qualidade da construção do conhecimento dos sujeitos.

Além desta reformulação feita pelas docentes, a Rede Marista, também repensou, diante dos decretos governamentais que estenderam a permanência de isolamento social, disponibilidade de conteúdo com uma abrangência maior, na não só em um formato assíncrono, em que não há interação com os sujeitos, mas também síncrono, ou seja, com um diálogo em tempo real, a partir da utilização da ferramenta do pacote Microsoft Teams, que permite a realização de videoconferências a qualquer lugar, com segurança e em grandes grupos, e para qual todos os estudantes receberam acesso ao se matricularem na escola.

Com essa reconfiguração, foi possivel estreitar as relações das docentes com as suas respec- 
tivas turmas, assim como perceber fragilidades no processo pedagógico, pois foram viabilizadas intervenções pontuais com os estudantes, dentro do tempo que foi disponibilizado, que inicialmente, foi de uma hora, dois dias por semana, sempre com o objetivo de atingir o grupo todo em cada vídeo aula em formato de live (ao vivo).

E como olhar para os estudantes com Necessidades Educacionais Especiais (NEE)? Fazendo- se presente em duas turmas. Além de considerar cada estudante durante as lives, a ação docente clamava pela especificidade de interação com os estudantes que, por hora, apresentam diferentes tipos de limitações, entre elas, a falta de interação com o grupo e a ausência da fala.

Para contemplar todo o grupo com estratégias heterogêneas e, principalmente, tendo como recurso mais próximo, a ferramenta Teams, fizeram-se oportunos encontros individuais com tais estudantes, fortalecendo, assim, os vinculos, auxiliando na aproximação com os novos recursos didáticos, adaptando-os paulatinamente às interações, assegurando a tranquilidade para docente e discente na acomodação desse novo processo.

Entretanto, esse momento também foi um marco para avaliar os processos que se haviam configurado desde o início da pandemia, pois a cada live se percebiam avanços pontuais nas aprendizagens e por consequência podia-se refinar cada vez mais as práticas pedagógicas, dentro das concepções docentes bem como alinhadas com os documentos pedagógicos da Rede em questão.

O tempo de isolamento foi aumentando e, sucessivamente, o ensino remoto foi se estendendo, assim como o periodo de aulas sincronas, para três vezes por semana, com duração de uma hora e trinta minutos, com o novo formato contemplando as aulas especializadas, conforme ofertado no currículo educacional da instituição, que abrange as áreas de música, educação física e inglês.

A partir dai, as aulas foram ficando cada vez mais dinâmicas e o olhar para as infâncias se alinhava aos processos, pois cabe ressaltar a importância de um currículo diversificado, em que as áreas do conhecimento conversam entre si, proporcionando momentos mais lúdicos para as crianças.
Uma das preocupações que foi se constituindo, foi com alguns estudantes que não acessavam os conteúdos e nem mesmo participavam das lives, o que foi se tornando uma grande inquietação para as docentes, que avistavam uma alfabetização já prejudicada com as incertezas do processo remoto, mas principalmente para esses estudantes que ficariam "à margem" no processo.

Já para outros estudantes que participavam das lives, mas que não se percebia grande envolvimento nas atividades, foi necessário trabalhar a autoestima, pois se viam distantes de seu grupo, diferenças talvez evidenciadas pelas familias, que faziam a comparação entre os pares, trazendo prejuizo a um marco crucial na faixa etária, que se constituem como sujeitos, entre seis e oito anos, período no qual se encontravam.

Como destacam Estanislau e Bressan:

\begin{abstract}
A fase de alfabetização é um período crucial para o desenvolvimento da autoestima. Como é neste momento que as crianças começam a se comparar com os demais e a receber maior (menor) reconhecimento dos professores e de outros adultos, a autoestima é posta à prova e, muitas vezes, apresenta uma queda comparada ao seu nível elevado nos anos pré-escolares. A criança fica mais sensivel a crítica, e é possivel que a comparação com os outros a faça desistir de atividades que gostava até então, por julgar-se incompetente (ESTANISLAU; BRESSAN, 2014, p. 89).
\end{abstract}

Ao longo do semestre além dessas configurações de turma, ainda era necessário lidar com as preocupações familiares, que enviavam dúvidas, aflições e sugestões na forma de trabalho, o que já era esperado, visto que a sala de aula agora se perpassava pelas suas casas e olhares.

Ao analisar o fato ocorrido, fica ainda mais evidente a necessidade de uma parceria entre as docentes, pois a frustração de uma professora diante das circunstâncias acolhidas por ela, muitas vezes eram as mesmas que de outra, a troca, assim, formava uma corrente de ajuda emocional, fortalecendo vínculos e amizades.

Os avanços da pandemia continuaram e o retorno as aulas presenciais se distanciava, assim o aumento do número de lives foi necessário, pois nessa modalidade via-se um trabalho mais satisfatório, então passou-se ao formato atual, 
acrescido de um dia com aulas em pequenos grupos, necessitando de disponibilidade, por parte das professoras, de uma tarde, e das crianças, de quarenta minutos.

Com o novo formato, foi necessário repensar o horário de trabalho, pois não era viável uma sobrecarga, mas sim uma solução temporária para um melhor aproveitamento das aprendizagens e que deveria ser pensado também para os educadores.

Portanto, reforçamos a convicção de que o trabalho do professor é fazer atividades que envolvam o grupo, a fim de inquietá-los em busca de novos conhecimentos, mas não esquecendo de que, nesse caso, tratava-se de crianças ainda em fases muito diferentes de formação umas das outra e, sendo assim, algumas intervenções didáticas realizadas que não levassem esse fato em consideração poderiam afetar alguns indivíduos de forma a imprimir marcas negativas em sua personalidade futura.

\section{Considerações finais}

Analisando os fatos apresentados, pode-se visualizar contribuições de suma importância para pensar na educação, que frente aos desafios encontrados durante o periodo de isolamento e com as constantes indefinições do governo, referentes à duração exata do período, devido aos avanços do vírus sobre a cidade de Porto Alegre, fez com que em muitos momentos mexessem com o emocional de todos envolvidos no processo

Inicialmente, em função de algo tão novo para todos, permitiu também refletir sobre as práticas pedagógicas no que tange à importância do planejamento, da execução e da avaliação do trabalho desenvolvido em uma perspectiva de regulação da própria aprendizagem.

Outro aspecto a destacar refere-se ao planejamento conjunto das docentes, em termos de seleção de habilidades e atividades pedagógicas para grupos heterogêneos. Esse processo requereu negociação, compatibilização de pontos de vista, visando a organizar propostas diferenciadas para alunos com diferentes niveis de necessidades, mantendo, no entanto, um eixo comum nas propostas, além de buscar não exigir algo além do que cada um podia render em termos de aprendizagem em cada momento e fazer avançar, tanto quanto possivel, quem podia avançar mais.

Acima de tudo, porém, evidenciou-se a necessidade de que emergisse neste momento uma organização familiar, por parte não só dos educandos, mas também dos educadores, que passaram a organizar e utilizar suas casas como extensão da sala de aula. Segundo Bene Catanante

\begin{abstract}
É certo que, quando você muda, tudo à sua volta muda. Seu olhar sobre as coisas e situações já não é o mesmo. Sentimentos, pensamentos, emoções, tudo muda também. É fundamental estar atento a isso para manter ima imagem coerente interna e externa. Essa coerência não precisa sempre aparentar o equilibrio, a perfeição (CATANANTE, 2000, p. 53).
\end{abstract}

Adaptar o espaço familiar às novas exigências profissionais, buscar novas ferramentas de trabalho, pensar a alfabetização no contexto da pandemia, exigiu um reinventar imediato das educadoras na busca de estratégias para uma maior excelência nos processos remoto. Como cita Bene Catanante (2000, p. 41): "Tem que se dispor a aprender e reaprender como um estudante principiante, entusiasmado e receptivo".

As incertezas acerca do cenário fizeram com que as docentes crescessem muito. Reacendendo a força do educador que ama o que faz, buscando nas relações o apoio enquanto equipe e trabalhando com a alma, o coração e a razão, com integralidade.

\section{Referências}

CATANANTE, Bene. Gestão do ser integral: como integrar alma, coração e razão no trabalho e na vida. São Paulo: Infinito, 2000.

DE LA TAILLE, Yves et alii. Piaget, Vygotsky e Wallon: teorias psicogenéticas em discussão. São Paulo: Summus, 1993

ESTANISLAU, Gustavo M.; BRESSAN, Rodrigo Affonseca (org.). Saúde mental na escola: o que os educadores devem saber. Porto Alegre: Artmed, 2014.

FERREIRO, Emilia. A escrita antes das letras. In: Instituto Vera Cruz. [S. I.], ago. 2016. Disponivel em: http:// site.veracruz.edu.br/instituto/wp-content/uploads/2016/08/Emilia-Ferreiro-A-Escrita-Antes-das-Letras-1.pdf. Acesso em: 23 abr. 2021. 
UNIÃO MARISTA DO BRASIL. Projeto Educativo do Brasil Marista: nosso jeito de conceber a Educação Básica. União Marista do Brasil. Brasília: UMBRASIL, 2010.

\section{Michelle Okrazewski da Cunha}

Especialista em Alfabetização e Letramento e Psicopedagogia Institucional pela Faculdade Educacional da Lapa (Fael), na Lapa, PR, Brasil; pedagoga pelo Centro Universitário Ritter dos Reis (UniRitter), em Porto Alegre, RS, Brasil; professora do ensino fundamental do Colégio Marista Assunção (CMA), em Porto Alegre, RS, Brasil.

\section{Caroline dos Santos Klein}

Especialista em Gestão da Educação em diferentes espaços educativos pelo Centro Universitário Ritter dos Reis (UniRitter), em Porto Alegre, RS, Brasil; Pedagoga com habilitação em anos iniciais e Supervisão Escola pelo Centro Universitário Ritter dos Reis (UniRitter), em Porto Alegre, RS, Brasil; professora do ensino fundamental do Colégio Marista Assunção (CMA), em Porto Alegre, RS, Brasil.

\section{Tanusa Dresch}

Especialista em Alfabetização e Letramento pelo Centro Universitário Leonardo da Vinci (IERGS), em Porto Alegre, RS, Brasil; pedagoga pela Universidade Luterana do Brasil (ULBRA), em Porto Alegre, RS, Brasil; professora do ensino fundamental do Colégio Marista Assunção (CMA), em Porto Alegre, RS, Brasil.

\section{Endereço para correspondência}

Michelle Okrazewski da Cunha

Colégio Marista Assunção

R. Dom Bosco, 103

Glória, 91110-460

Porto Alegre, RS, Brasil

Os textos deste artigo foram revisados pela Poá Comunicação e submetidos para validação das autoras antes da publicação. 